\title{
PENGENALAN KEWIRAUSAHAAN DIGITAL DIMASA PANDEMI MELALUI KEGIATAN FOTOGRAFI
}

\author{
Tri Nugroho Budi Santoso
}

\begin{abstract}
Program Studi Pendidikan Ekonomi, Fakultas Keguruan dan Ilmu Pendidikan Universitas Kristen Satya Wacana, J1. Diponegoro No.52-60, Salatiga, Sidorejo, Salatiga, Kec. Sidorejo, Kota Salatiga, Jawa Tengah 50711, Indonesia
\end{abstract}

Email: tri.budi.santoso@uksw.edu

\begin{abstract}
ABSTRAK
Masa pandemi menjadi faktor utama dalam berbagai perubahan yang terjadi di berbagai bidang kehidupan, salah satu yang terdampak adalah ekonomi dan pendidikan. Kewirausahaan digital menjadi wacana baru dalam mengatasi masalah ekonomi di Indonesia. Tujuan penelitian ini untuk mengkolaborasikan kegiatan kompetisi fotografi untuk mengenalkan kewirausahaan digital dimasa pandemi. Penelitian ini menggunakan pendekatan penelitian campuran yaitu perpaduan antara metode penelitian kualitatif dan kuantitatif. Kualitatif dengan menggunakan jenis penelitian kualitatif deskriptif untuk menggambarkan atau menguraikan suatu fenomena pengenalan kewirausahaan digital dimasa pandemi melalui kegiatan fotografi. Metode kuantitatif menggunakan analisis statistika deskriptif untuk menghitung data responden yang diukur melalui skala linkert. Berdasarkan hasil analisis diketahui kewirausahaan digital dapat dikenal dengan berbagai teknologi sederhana, berbagai teknik fotografi secara tidak langsung dapat mengenalkan kegiatan berwirausaha secara digital lebih mendalam sekaligus memberikan motivasi dalam merintis kegiatan berwirausaha. Berdasarkan data responden, yang diperoleh dari instrumen dengan skala likert diketahui skor 91 dari skor maksimal 100 terletak pada daerah mendekati Sangat Setuju. Simpulan yang dapat diambil kegiatan kompetisi fotografi yang dilakukan dapat memberikan wawasan tentang kewirausahaan digital.
\end{abstract}

Kata kunci: Kewirausahaan Digital, Kompetisi Fotografi, Masa Pandemi

\begin{abstract}
The pandemic period is a major factor in various changes that occur in various fields of life, one of which is affected by the economy and education. Digital entrepreneurship is a new discourse in overcoming economic problems in Indonesia. The purpose of this research is to collaborate with photography competition activities to introduce digital entrepreneurship during the pandemic. This study uses a mixed research approach, namely a combination of qualitative and quantitative research
\end{abstract}


methods. Qualitatively by using descriptive qualitative research to describe or describe a phenomenon of introducing digital entrepreneurship during a pandemic through photography activities. The quantitative method uses descriptive statistical analysis to calculate the respondent's data as measured by the linkert scale. Based on the results of the analysis, it is known that digital entrepreneurship can be recognized by various simple technologies, various photography techniques can indirectly introduce entrepreneurship activities digitally more deeply as well as provide motivation in pioneering entrepreneurial activities. Based on respondent data, obtained from instruments with a Likert scale, it is known that a score of 91 out of a maximum score of 100 lies in the area close to Strongly Agree. The conclusions that can be drawn from the photography competition activities carried out can provide insight into digital entrepreneurship.

Keywords: Digital Entrepreneurship, Photography Competition, Pandemic Period

\section{PENDAHULUAN}

Pandemi yang terjadi mulai tahun 2020 tidak dapat di pungkiri berpotensi melumpuhkan sektor ekonomi di Indonesia. Dampak sektor perekonomian di Indonesia di masa pandemi antara lain PHK, penurunan impor, dan inflasi (Yamali \& Putri, 2020). Dampak tersebut sangat dirasakan oleh masyarakat ekonomi menengah ke bawah ditambah dengan penanganan pemerintah Indonesia yang dinilai lambat dalam merespon pandemi COVID-19 pada awal penyebarannya pada Maret 2020, baru mengeluarkan beberapa kebijakan seperti jarak fisik, pembatasan sosial berskala besar (PSBB) dan jaring pengaman sosial (Roziqin et al., 2021).

Berbagai program bantuan yang diberikan pemerintah tentu sangat membantu ekonomi masyarakat dalam kurun waktu sementara. Namun demikian diperlukan trobosan-trobosan untuk dapat memberikan jalan keluar bagi kondisi ekonomi yang stagnan di pemerintah. Salah satu diantarannya adalah inovasi kegiatan wirausahan berbasis digital.

Kondisi tersebut sejalan dengan penelitian Mansour (2021) menjelaskan bahwa negara-negara berpenghasilan rendah dan menengah ke bawah telah secara signifikan menanggapi lonjakan kebutuhan alat pembayaran digital selama pandemi dibandingkan dengan negara-negara berpenghasilan menengah ke atas dan berpenghasilan tinggi. Berdasarkan hal tersebut kegiatan berwirausaha berbasis digital mulai banyak berkembang di seluruh Negara di dunia termasuk Indonesia. Berbagai bentuk model kewirausahaan digital bermuculan mulai dari marketplace besar seperti shopee, bukalapak, tokopedia, sampai dengan Usaha Mikro Kecil dan Menengah (UMKM) mulai mengadaptasi berbagai teknologi untuk meningkatgkan produktivitas.

Berbagai macam inovasi kewirausahaan digital ini menjadi hal menarik untuk dipelajari, salah sutunya di kalangan akademisi. Bagiamana pendidik dapat melatih peserta didik untuk dapat mengenal fenomena yang terjadi khususnya 
pada kewirausahaan digital dimasa pandemi. Adapun lingkup kewirausahaan berbasis digital menurut Kraus et al. (2019), meliputi model bisnis digital; proses kewirausahaan digital; strategi platform; ekosistem digital; pendidikan kewirausahaan; dan kewirausahaan digital sosial.

Kebijakan pemerintah yang membatasi kegiatan pendidikan juga memiliki dampak negatif dalam proses pembelajaran yang dilakukan. Ditambah lagi dengan kebijakan merdeka belajar yang harus dapat dikaji secara mendalam agar kurikulum pembelajaran yang diberikan benar-benar dapat menghadirkan pembelajaran yang berkualitas. Pada kurikulum merdeka belajar saat ini peserta didik membutuhkan model pembelajaran yang menyenangkan dan berbasis teknologi agar tetap dapat berinteraksi dengan pendidik.

Berdasarkan hal latar belakang tersebut tujuan penelitian ini untuk mengkolaborasikan kegiatan kompetisi fotografi untuk mengenalkan kewirausahaan digital dimasa pandemi. Fotografi memiliki keunikan untuk membantu kita dalam proses pengamatan yang biasanya cepat berlalu. Fotografi juga memungkinkan kita untuk merekam perilaku dalam konteks situasionalnya, melakukan kegiatan refleksi, sebagai informan, dan penggunaan perilaku atau situasi sebagai sebuah ilustrasi (Basil, 2011). Hal ini diperkuat dengan pendapat Machin et al. (2020), yang menyatakan bahwa fotografi adalah metode penelitian yang unik dan dapat diakses untuk memahami masalah sosial kesejahteraan.

Berdasarkan latar belakang tersebut penulis tertarik untuk menulis tentang pengenalan kewirausahaan digital dimasa pandemi melalui kegiatan fotografi, yang diukur dengan pengalaman dan pemahaman peserta didik dalam mengikuti sebuah kompetisi fotografi. Untuk menanamkan berbagai konten digitalisasi dalam dunia wirausaha juga dibat kriteria yang medukung dalam kegiatan kewirausahaan berbasis digital. Penelitian ini diharapkan dapat memberikan manfaat baik kalangan akademisi maupun generasi muda dalam bidang kewirausahaan

\section{METODE}

Penelitian ini menggunakan pendekatan metode penelitian campuran (Mixed Methods Research) yaitu bentuk kombinasi antara metode penelitian kualitatif dan metode penelitian kuantitatif. Metode kualitatif dengan menggunakan jenis penelitian kualitatif deskriptif untuk menggambarkan atau menguraikan suatu fenomena yang belum diketahui tentang pengenalan kewirausahaan digital dimasa pandemi melalui kegiatan fotografi. Sumber data yang digunakan adalah sumber data primer diperoleh dari peserta lomba kegiatan fotografi yang terdiri dari perwakilan 4 sekolah. Sedangkan teknik yang dilakukan peneliti dalam memperoleh data adalah dengan melakukan observasi, wawancara, serta dokumentasi, dan angket. Analisis data, metode kualitatif menggunakan model Miles 
dan Huberman yaitu dengan tahaptahap pengumpulan data (Data Collection), reduksi data (Data Reduction), penyajian data (Data Display), dan penarikan kesimpulan (Verification). Metode kuantitatif menggunakan analisis Statistika deskriptif untuk menghitung data responden yang diukur melalui skala linkert.

Pelaksanaan penelitian dapat diuraikan dalam waktu kegiatan sebagai berikut:

Tabel 1. Waktu penelitian

\begin{tabular}{ll}
\hline Kegiatan & Jadwal \\
\hline $\begin{array}{l}\text { Pelaksanaan Perlombaan } \\
\text { Fotografi }\end{array}$ & Maret 2021 \\
$\begin{array}{l}\text { Refleksi Foto } \\
\text { Kewirausahaan }\end{array}$ & April 2021 \\
Analisis Data & April 2021 \\
Penyusunan Laporan & April 2021 \\
\hline
\end{tabular}

Sumber: Data laporan kegiatan

Perlaksanaan

perlombaan dilakukan secara dalam jaringan, bentuk kegiatan berupa pengambilan foto tentang kewirausahaan sebagai bahan kompetisi. Alat dan bahan yang digunakan dalam kegiatan penelitian ini peserta kompetisi dapat menggunakan perangkat smatphone untuk mengambil gambar dan mengirimkan hasil karya original dalam format jpg.

\section{HASIL DAN PEMBAHASAN}

\section{Analisis Hasil Peserta}

Dari hasil foto yang diperoleh peserta didik mampu memperoleh hasil sesuai dengan topic menghadikan kewirausaan secara digital dimasa pandemi. Melalui kegiatan fotografi yang menyenangkan disamping dapat menyalurkan kegemaran atau hobi peserta didik, secara tidak langsung diharapkan dapat menambah wawasan peserta tentang kewirausahaan dalam masa pandemi. Kegiatan fotografi di era digital merupakan kegiatan yang sangat menyenangkan dan mudah. Seorang fotografer dengan perngakat yang dimiliki hanya perlu memotret, memeriksa hasilnya, dan menghapusnya jika mereka tidak puas dengan hasilnya, atau, mereka dapat menyimpannya ketika gambar memenuhi harapan mereka (Gunawan, 2013).

Namun demikian peserta juga memerlukan beberapa pemahaman dasar tentang fotografi agar hasil yang didapat dapat bersaing dalam kompetisi. Seorang fotografer harus menguasai dan memaksimalkan penggunaan diafragma, kecepatan rana, ISO, dan semua teknik lain yang dapat memaksimalkan hasil foto yang akan di ambil (Gunawan, 2013). Hal ini juga menjadi keunikan dari penelitian yang dilakukan yaitu dengan menjadikan bidang fotografi menjadi media pengenalan kewirausahaan yang menyenangkan.

Selain teknik foto yang menjadi target utama kegiatan ini adalah peserta didik dapat belajar tentang kewirausahaan digital yang mampu bersaing di masa pandemi. Salah satunya pemahaman e-commerce dalam kegiatan wirausaha. Pemanfaatan e-commerce relatif lebih mudah bagi para wirausahawan dalam melakukan transaksi maupun penawaran produknya (Fauzia, 2016). Hal ini tentu sangat dibutuhkan pada masa pademi saat ini. Selain $e$ commerce kompetensi tentang digital marketing menjadi hal utama dalam kegiata ini. 
Melalui kegiatan fotografi peserta secara langsung dapat melihat praktik pemasaran digital yang dilakukan oleh wirausahawan untuk tetap mempertahankan bisnisnya dalam masa pandemi. Wijoyo et al. (2020) menambahkan melalui digital marketing calon pembeli dapat memperoleh seluruh informasi mengenai produk dan bertransaksi melalui internet, memantau, dan menyediakan kebutuhan calon konsumen dengan penggunaan media sosial atau marketplace yang menyediakan pelayanan digital. Hal ini dapat menjadi representatif yang dapat diterima peserta secara langsung di lapangan bagaimana proses kewirausahaan digital dapat terjadi.

Dari berbagai macam hasil karya peserta yang telah ditelaah semua foto memiliki nilai dari aspek kewirausahaan secara digital. Mulai dari segi pemasaran online yang terlihat dari adanya elemen perusahaan Grab atau Gojek, teknik pemesanan secara digital melalui marketplace Grab Food atau Go Food. Cara pembacaran melalu e-commerce seperti shoppe pay menjadi representative bagaimana peserta sebagai sampel penelitian belajar secara langsung kewirausahaan digital.

\section{Refleksi Foto Kewirausahaan}

Dalam rangka memperkuat pemahaman peserta tentang Kewirausahaan Digital. Dilakukan reflesi kegiatan yang melibatkan dosen Program Studi Pendidikan Ekonomi untuk memberikan refleksi tentang pentingan kewirausahaan digital di masa pandemi. Berikut dokumentasi kegiatan yang dilakukan melalui zoom meeting.

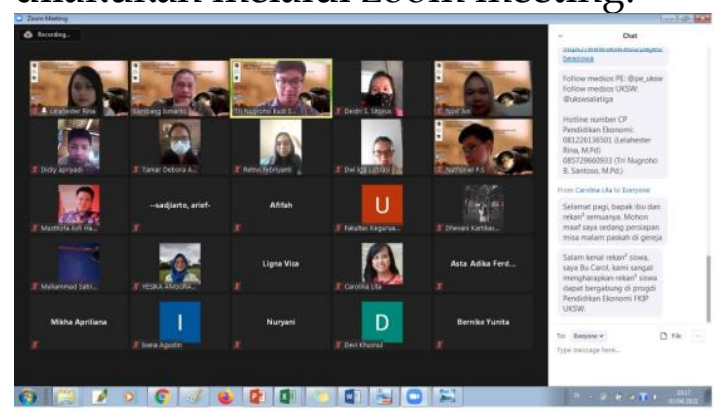

Gambar 1. Kegiatan refleksi foto kewirausahaan

Gambar diatas menjelaskan kegiatan refleksi hasil foto sekaligus menambahkan wawasan tentang kewirausahaan digital dapat bertahan di masa pandemi. Erlyana \& Hansen (2021), hasil kegiatan pelatihan tentang kompetensi fotografi dan videografi dapat digunakan dalam pembekalan usahan dimasa pandemi saat ini. Melalui kegiatan refleksi terjadi interaksi menarik mulai dari menceritakan pengalaman peserta saat melaksanakan kegiatan fotografi dan implementasi teoritis dari ilmu kewirausahaan dari narasumber.

\section{Analisis Output Kegiatan}

Untuk mengukur respon dari peserta di lakukan reflesi kegiatan di akhir acara dengan memberikan kesempatan pada peserta untuk memberikan kesan peserta pada kegiatan yang telah dilakukan. Adapun tiga kesan dari peserta kegiatan sebagai berikut:

"Perlombaan yang diikuti sangat menarik dan sangat mudah untuk dilakukan karena hanya membutuhkan smartphone untuk mengambil foto, selain itu kita bisa mengenal kegiatan kewirausahaan 
disekitar yang masih bertahan mesipun dalam keadaan pandemi." (MAP, 1/04/2021)

"Menurut saya saya dapat belajar banyak tentang kewirausahaan digital, dimana saya harus dapat mencari foto dengan kriteria kegiatan usaha yang berbasis digital. Selain itu saya juga dapat menyalurkan hobi saya dalam dunia fotografi dan mengimplemenasikan ilmu yang saya dapat dari bangku sekolah terutama di jurusan multimedia" (AR, 1/04/2021)

"Perlombaan ini sangat menarik, pengalaman saya sendiri yang memiliki usaha kecil-kecil dapat langsung mengambil gambar dari usaha saya sendiri dan memang pemasaran online saat ini menjadi hal yang penting untuk usaha saya. Sehingga melalui kegiatan ini saya semakin dapat mendalami bisnis yang saya tekuni." (DA, 1/04/2021)

Berdasarkan hasil wawancara yang dilakukan dapat disimpulkan beberapa hal penting tentang pengalam yang di dapat peserta setelam mengikuti kegiatan: kewirausahaan digital saat ini dapat dikenal dengan berbagai teknologi sederhana dalam kehidupan kita sehari-hari termasuk pada kegiatan fotografi melalui smartphone terutama pada kalangan milenial. Hal ini sesuai dengan pendapat Caniago \& Hayati (2019), yang menjelaskan bahwa potensi wirausahawan muda tersebut akan terus bertumbuh melalui kewirausahaan teknologi digital, oleh karena sumberdaya pengembangan kewirausahaan yang diminati oleh kaum milenial. (2) melalui fotografi dengan berbagai teknik pengambilan gambar yang ada didalamnya, kita dapat mengenal kegiatan berwirausaha secara digital lebih mendalam. Hal tersebut didukung Nurlaily et al. (2021) bahwa dengan pengetahuan dan keahlian pengambilan foto produk dapat membuat branding produk kewirausahaan digital lebih menarik. (3) kegiatan fotografi dalam kewirausahaan digital dalam memberikan motivasi untuk dapat mengembangkan minat seseorang dalam merintis kegiatan berwirausaha. Hal tersebut didukung oleh Arifah (2020), Siswa yang berwirausaha di era revolusi industri 4.0 diarahkan pada kewirausahaan dengan pendekatan kontekstual yakni penggunaan teknologi sebagai alat berinovasi dan memasarkan produk/jasa.

Untuk memperkuat tanggapan perserta disebarkan angket kepuasan sekaligus presensi kegiatan untuk mengetahui tanggapan keseluruhan peserta. Adapun angket yang dibuat berpedoman pada skala linkert menurut Arifin (2014), agar skala Likert berkualitasada beberpa aspek yang perlu diperhatikan: pernyataan harus didasarkan pada sesuatu yang diingikan buken berdasarkan fakta, 2) pernyataan harus jelas tanpa ada pemaknaan ganda 3) kecenderungan jawaban dapat terjadi di semua sudut kontinum 4) instrument diharapkan memiliki 2 kelompok jawaban bersifat positif maupun negatif 5) setiap pertanyaan hanya dapat mengandung sebuah variabel sikap. Angket yang disusun akan menjadi skala pengukuran dari efektifitas 
kegiatan fotografi pada pemahaman kewirausahaan digital.

Pernyataan yang diberikan disampaikan bersamaan dengan kegiatan refleksi kegiatan lomba fotografi lebih tepatnya pada akhir acara. Instrunmen dibuat dengan pernyataan akhir untuk efektivitas kegiatan "kompetisi fotografi dengan tema kewirausahaan digital dapat menambah wawasan saya tentang bentuk kewirausahaan digital dalam masa pandemi". Adapun pilihan jawaban yang dikembangkan berdasarkan skala Likert, Sangat Setuju (5 point), Setuju (4 point), Ragu-Ragu (3 point), Tidak Setuju (2 point), dan Sangat Tidak Setuju (1 point). Hasil yang diperoleh adalah Sangat Setuju (12 Responden), Setuju (7 Responden), Ragu-Ragu (1 Responden), Tidak Setuju (0 Responden), dan Sangat Tidak Setuju (0 Responden). Jumlah skor ideal untuk seluruh item $5 \times 20=100$. Jumlah skor yang diperoleh dari penelitian $=91$

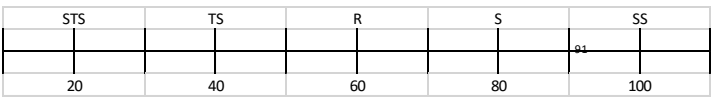

Jadi berdasarkan data yang diperoleh dari 20 responden, skor 91 terletak pada daerah mendekati Sangat Setuju. Berdasarkan hasil respon peserta pada kegiatan yang dilakukan terbukti bahwa melalui kegiatan kompetisi fotografi dapat memberikan wawasan tentang kewirausahaan digital dalam masa pandemi.

Berdasarkan pembahasan dan analisis yang telah dilakukan berbagai rangkaian kegiatan dalam kompetisi fotografi kewirausahaan digital ini terbukti memiliki manfaat pada pengenalan kewirausahaan digital dalam masa pandemi. Selain itu memberikan wawasan berbagai potensi bisnis yang mungki ada dalam kondisi pandemi dengan memanfaatkan teknologi. Melalui media fotografi memiliki dampak pada bidang marketing untuk melakukan kegiatan penyebaran konten yang memungkinkan perusahaan untuk menawarkan keterampilan desain mutakhir.

Selain itu berdasarkan analisa dari berberapa pendapat yang disampaikan responden dari pengalaman yang peroleh kegiatan fotografi dapat memberikan gambaran tentang tantangan kewirausahaan di masa depan. Hal tersebut selarah dengan pendapat Diani \& Setiawan (2018), yang menjelaskan bahwa melalui kegiatan pelatihan fotografi dapat meningkatkan kemampuan individu untuk memperbaiki kinerja dalam berwirausaha. Sekaligus menjadi bekal bagi perserta atau calon wirausahawan untuk memperoleh ilmu tambahan tentang kewirausahaan digital.

\section{KESIMPULAN}

Berdasarkan kegiatan yang telah dilakukan dilakukan analisis data secara kualitatif melalui observasi, wawancara, dan analisis dokumen. Adapun beberapa hasil yang diperoleh (1) kewirausahaan digital saat dapat dikenal dengan berbagai teknologi sederhana dalam kehidupan kita sehari-hari, (2) berbagai teknik pengambilan gambar dalam kegiatan fotografi secara tidak 
langsung dapat mengenalkan kegiatan berwirausaha secara digital lebih mendalam, (3) kegiatan fotografi dalam kewirausahaan digital dapat memberikan motivasi seseorang dalam merintis kegiatan berwirausaha. Berdasarkan data responden, yang diperoleh dari instrumen dengan skala likert diketahui skor 91 terletak pada daerah mendekati Sangat Setuju. Sehingga dapat disimpulkan kompetisi fotografi yang dilakukan dapat memberikan wawasan tentang kewirausahaan digital.

\section{DAFTAR PUSTAKA}

Arifah, Z. (2020). Membangun Karakter Kewirausahaan Melalui Studentpreneurship Era Revolusi Industri 4 . 0 (Studi Lapangan Pada SMP Islam Ngadirejo Temanggung). ASNA: Jurnal Kependidikan Islam Dan Keagamaan, 2(2), 28-36.

Arifin, Z. (2014). Penelitian Pendidikan: Metode dan Paradigma Baru. Remaja Rosdakarya.

Basil, M. (2011). Use of photography and video in observational research. Qualitative Market Research: An International Journal, 14(3), 246-257. https:// doi.org/10.1108/1352275 1111137488

Caniago, I., \& Hayati, K. (2019). Kewirausahaan Teknologi Digital. Pemberdayaan Pebisnis Milenial, 3(1), 1-6.

Diani, F., \& Setiawan, I. (2018). Pemanfaatan Software Fotografi Untuk Berwirausaha Mobile Digital Printing. DIFUSI, 1(2), 47-
54.

Erlyana, Y., \& Hansen, H. (2021). Pelatihan Fotografi Dan Videografi Secara Virtual Dalam Peningkatan Kemampuan Diri Pada Pandemic Covid-19. Jurnal Pengabdian Dan Kewirausahaan, 5(1), 47-54. https://doi.org/10.30813/jpk.v5i 1.2725

Fauzia, I. Y. (2016). Pemanfaatan ecommerce dan m-commerce dalam bisnis di kalangan wirausahawan perempuan. Journal of Business $\mathcal{E}$ Banking, 5(2), 237-256.

https://doi.org/10.14414/jbb.v5i 2.705

Gunawan, A. P. (2013). Pengenalan Teknik Dasar Fotografi. Humaniora, 4(1), 518-527. https://doi.org/10.21512/huma niora.v4i1.3460

Kraus, S., Palmer, C., Kailer, N., Kallinger, F. L., \& Spitzer, J. (2019). Digital entrepreneurship: A research agenda on new business models for the twentyfirst century. International Journal of Entrepreneurial Behaviour and Research, 25(2), 353-375. https://doi.org/10.1108/IJEBR06-2018-0425

Machin, J. E., Moscato, E., \& Dadzie, C. (2020). Visualizing food: photography as a design thinking tool to generate innovative food experiences that improve food well-being. European Journal of Marketing, 55(9), 2515-2537. https://doi.org/10.1108/EJM-022020-0141 
Mansour, H. (2021). How successful countries are in promoting digital transactions during COVID-19. Journal of Economic Studies. https:// doi.org/10.1108/JES-102020-0489

Nurlaily, F., Asmoro, P. S., \& Aini, E. K. (2021). Pelatihan Teknik Foto Produk Menggunakan Smartphone Untuk Meningkatkan Visual Branding Usaha Rintisan. Jurnal Pengabdian Kepada Masyarakat, 1(3), 347-356.

Roziqin, A., Mas'udi, S. Y. F., \& Sihidi, I. T. (2021). An analysis of Indonesian government policies against COVID-19. Public Administration and Policy, 24(1), 92-107.

https:// doi.org/10.1108/pap-082020-0039

Wijoyo, H., Ariyanto, A., Sunarsi, D., \& Faisal Akbar, M. (2020). Pelatihan Pembuatan Konten Digital Marketing Dalam Meningkatkan Kompetensi Mahasiswa. Ikra-Ith Abdimas, 3(3), 169-175.

Yamali, F. R., \& Putri, R. N. (2020). Dampak Covid-19 Terhadap Ekonomi Indonesia. Ekonomis: Journal of Economics and Business, 4(2), 384-388. https:// doi.org/10.33087/ekono mis.v4i2.179 